DOI: $10.18027 / 2224-5057-2021-11-3 s 2-36$

Цитирование: Орлова Р.В., Гладков О.А., Кутукова С.И., Копп М.В., Королева И.А., Ларионова В.Б. и соавт. Практические рекомендации по лечению анемии при злокачественных новообразованиях. Злокачественные опухоли : Практические рекомендации RUSSCO \#3s2, 2021 (том 11). 36

\title{
ПРАКТИЧЕСКИЕ РЕКОМЕНДАЦИИ ПО ЛЕЧЕНИЮ АНЕМИИ ПРИ ЗЛОКАЧЕСТВЕННЫХ НОВООБРАЗОВАНИЯХ
}

Коллектив авторов: Орлова Р.В., Гладков О.А., Кутукова С.И., Копп М.В., Королева И.А., Ларионова В.Б., Моисеенко В.М., Поддубная И.В., Птушкин В.В.

Ключевые слова: поддерживающая терапия, анемия, эритропоэтин, железодефицитная анемия, анемия онкологических больных

Анемия при злокачественных новообразованиях (АЗН) определяется как снижение концентрации гемоглобина ниже нормального значения (обычно 120г/л) или более чем на 20 г/л от исходного значения и может быть обусловлена как наличием самой опухоли, так и её лечением. Слабая степень анемии представляет собой снижение концентрации гемоглобина в диапазоне от 100 до 119 г/л, анемия средней степени - концентрация гемоглобина от 80 до 99г/л, тяжёлая анемия - ниже 80 г/л.

Согласно Common Terminology Criteria for Adverse Events (СТCAE) v. 5.0 выделяют 5 степеней тяжести анемии (табл. 1).

Таблица 1. Классификация анемии по критериям СTCAE v. 5.0

\begin{tabular}{|l|l|l|}
\hline $\begin{array}{l}\text { Cтепень тяжести } \\
\text { (grade) }\end{array}$ & Уровень Нb (г/л) & Комментарии \\
\hline 1 & $<100 г / л$ & - \\
\hline 2 & $80-100 г / л$ & - \\
\hline 3 & $<80 г / л$ & Показана гемотрансфузия \\
\hline 4 & $\begin{array}{l}\text { Жизнеугрожающее состояние, необходимо срочное } \\
\text { медицинское вмешательство }\end{array}$ & - \\
\hline 5 & Смерть & - \\
\hline
\end{tabular}

Клиническая значимость анемии определяется:

- отрицательным влиянием на качество жизни онкологических больных с развитием слабости; 
- отрицательным влиянием на продолжительность жизни при большинстве типов опухолей;

- снижением эффективности противоопухолевого лечения (отдельных цитотоксических препаратов и лТ).

\section{1. ДИАГНОСТИКА}

\section{1. Анамнез}

При сборе анамнеза у больных с анемией необходимо оценить:

- Возможность наследственной анемии или гемоглобинопатии;

- Характер идлительность предшествуюей противоопухолевой терапии (вид лекарственной терапии, количество курсов, миелотоксичность, включение препаратов платины);

- Наличие острого или хронического кровотечения;

- Хронические воспалительные заболевания почек;

- Наличие аутоиммунных заболеваний.

\section{2. Лабораторные показатели}

- Общий анализ крови с определением концентрации гемоглобина (Hb), количества эритроцитов и ретикулоцитов, гематокрита (Hct), среднего объёма эритроцита (MCV), среднего содержания Нb в эритроците (MCH), средней концентрации Нb в эритроците (МСНC), среднего содержания Нb в ретикулоците;

- Исследование костного мозга - по показаниям;

- Оценка показателей обмена железа: содержание сывороточного ферритина с поправкой на содержание С-реактивного белка (повышение ферритина как белка острой фазы при воспалении), насыщение сывороточного трансферрина железом, содержание в крови фолатов и витамина В12;

- Оценка возможности скрытого кровотечения из ЖКТ (пробы на скрытую кровь в кале, эндоскопическое исследование), почечной недостаточности (клиренс креатинина <60 мл/мин.) с нарушением продукции эндогенного эритропоэтина;

- Проба Кумбса (при хроническом лимфолейкозе, неходжкинских лимфомах, аутоиммунных заболеваниях в анамнезе);

- Определение концентрации эндогенного эритропоэтина (при подозрении на миелодиспластический синдром).

Диагностику анемии и выявление причин необходимо проводить до проведения заместительных трансфузий эритроцитов (если нет экстренных показаний) или назначения эритропоэстимулирующих препаратов (ЭСП) и препаратов железа. Алгоритм диагностики анемии у онкологического больного представлен на рис. 1. 


\section{2. ЛЕЧЕНИЕ}

\section{1. Гемотрансфузии}

Традиционным методом коррекции сниженного Нb и жизнеугрожающих ситуаций, связанных с острой кровопотерей (обширные операции), являются заместительные трансфузии эритромассы. Однако для лечения анемии, связанной с опухолевым процессом (распад опухоли, интоксикация) и противоопухолевым лечением, гемотрансфузии не являются безопасным и эффективным методом. Переливания эритромассы могут сопровождаться гемолитическими реакциями, в том числе фатальными (частота - 1:1000), трансфузионными поражениями лёгких (частота - 1:5000), бактериальной контаминацией, в том числе фатальным сепсисом (частота - 1:10000), передачей вирусов гепатита В (частота - 1:30000), гепатита С и вируса иммунодефицита человека (частота - 1:1000000). Кроме того, многие потенциально опасные вирусные инфекции в настоящее время у доноров не тестируются. Наряду свышесказанным, иммунодепрессия, вызванная переливанием эритроцитов, приводит к повышению риска тромбозов, инфекционных осложнений и снижением безрецидивной и общей выживаемости при ряде опухолевых заболеваний (колоректальный рак, рак мочевого пузыря). Повышение концентрации Нb после гемотрансфузий является кратковременным, и для поддержания его нормального значения их необходимо повторять. В связи с этим ВОЗ рекомендует максимально регламентировать заместительные гемотрансфузии у онкологических больных и использовать альтернативные методики коррекции Нb.

Согласно приказу Министерства Здравоохранения Российской Федерации от 03.06.2013 г. № $348 \mathrm{H}$, гемотрансфузии при снижении концентрации $\mathrm{Hb}<70-80$ г/л показаны только в случае острых постгеморрагических анемий при одномоментном снижении гематокрита $\leq 25 \%$. При хронических анемиях главной задачей является устранение причины, вызвавшей анемию, и гемотрансфузии назначаются только для коррекции клинически значимых симптомов, обусловленных гипоксией вследствие снижения Нb и не поддающихся патогенетической терапии.

\section{2. Лекарственная терапия}

\subsection{1. Эритропоэз-стимулирующие препараты}

\subsubsection{1. Показания}

Альтернативным методом коррекции АЗН является назначение ЭСП в монотерапии или в комбинации с препаратами железа. Их применение показано при симптомной анемии и $\mathrm{Hb}<100$ г/л и всем пациентам с анемией тяжелой степени. В случае отсутствия эффекта (увеличение Нb менее, чем на 10 г/л при исходном уровне $\mathrm{Hb}<100$ г/л) лечение ЭСП должно быть прекращено через 8 недель. Использование ЭСП позволяет повысить продукцию эритроцитов костным мозгом и увеличить содержание Нb без переливания донорских эритроцитов. Результаты контролируемых исследований показали, что применение ЭСП при АЗН, а также при анемии, вызванной ХТ, повышает концентрацию Нb в 60-70\% случаев и сопровождается существенным снижением потребности в заместительных гемотранс- 
фузиях (относительный риск 0,64; $95 \%$ ДИ 0,6-0,68). У больных с солидными опухолями и больных, получающих платиносодержащуюХТ, применение ЭСп более эффективно, чем при других типах опухолей и других видах ХТ. В ряде исследований продемонстрировано улучшение качества жизни при применении ЭСП. Однако в других исследованиях различия в показателях качества жизни признаны незначимыми.

Применение ЭСП повышает вероятность венозных тромбоэмболических осложнений (ВТЭО), относительный риск которых увеличивается на $67 \%$ по сравнению с плацебо (ОР 1,67; $95 \%$ ДИ: 1,35-2,06). Однако назначение эритропоэтинов не требует дополнительной профилактики ВТЭО. Влияние ЭСП на выживаемость онкологических больных изучается, однако результаты исследований неоднозначны. Данные трёх мета-анализов показали негативное влияние ЭСП на общую выживаемость, а результаты двух других мета-анализов подобного влияния не выявили. Однако во всех мета-анализах не было выявлено значимого негативного влияния ЭСП у больных, получающих ХТ. В связи с этим большинство экспертов считает нецелесообразным применение ЭСП у больных, не получающих XТ или ХлТ, за исключением пациентов с миелодиспластическим синдромом.

\subsubsection{2. Противопоказания}

- Известная гиперчувствительность к ЭСП или их компонентам;

- Неконтролируемая АГ;

- Высокий риск тромбоэмболических осложнений (тромбоз в анамнезе, обширное хирургическое вмешательство, длительная иммобилизация или ограничение активности, лечение талидомидом или леналидомидом в комбинации с доксорубицином и ГКС; данные о роли профилактического использования антикоагулянтов или аспирина отсутствуют);

- Хроническая почечная недостаточность (возможны случаи истинной эритроцитарной аплазии, вызванной нейтрализующими антиэритропоэтиновыми антителами; случаев истинной эритроцитарной аплазии среди онкологических больных не описано).

\subsubsection{3. Осложнения}

- Редкие аллергические реакции, включая удушье, кожную сыпь и крапивницу;

- Артралгии;

- Периферические отёки;

- Незначительная и преходящая боль в месте инъекции.

Рекомендуемые дозы ЭСП и принципы их коррекции у взрослых онкологических больных, получающих X Т, представлены в табл. 2.

\subsection{2. Препараты железа}

У части больных на фоне терапии ЭСП быстро развивается абсолютный или функциональный дефицит железа, в связи с чем необходимо исходное и периодическое измерение насыщения железом сывороточного трансферрина, содержания сывороточного ферритина и С-реактивного белка. Показателями нарушения обмена железа являются содержание 
сывороточного ферритина <100 нг/мл и насыщения железом сывороточного трансферрина $<20 \%$. Содержание сывороточного ферритина $<100$ нг/мл у онкологического больного свидетельствует об абсолютном дефиците железа и необходимости терапии препаратами железа; предпочтительны в/в лекарственные формы, т. к. при приёме внутрь железо плохо всасывается. Более высокое содержание сывороточного ферритина (100-800 нг/мл) и насыщение железом сывороточного трансферрина <20\% свидетельствует о функциональном дефиците железа.

У больных с анемией и дефицитом железа парентеральное введение препаратов железа приводит к значительно большему повышению концентрации Нb, чем без применения железосодержащих препаратов или при назначении препаратов железа внутрь. Поддержка препаратами железа уменьшает также число больных, нуждающихся в трансфузиях эритроцитов.

В связи с возможным взаимодействием железа и некоторыхцитостатиков (антрациклины, препараты платины) необходимо воздерживаться от введения препаратов железа в дни введения противоопухолевых препаратов.

Рекомендуемые дозы и режим введения препаратов железа представлены в табл. 3.

В табл. 4 представлена сводная информация о лекарственных препаратах, рекомендуемых для лечения анемии у онкологических больных.

Таблица 2. Рекомендуемые дозы эритропоэз-стимулирующих препаратов и принципы их коррекции у взрослых онкологических больных, получающих химиотерапию

\begin{tabular}{|c|c|c|c|c|}
\hline Параметры & Эпоэтин альфа-1 & Эпоэтин бета-1 & Эпоэтин тета-1 & $\begin{array}{l}\text { Дарбэпоэтин } \\
\text { альфа-1 }\end{array}$ \\
\hline Начальная доза & $\begin{array}{l}150 \text { ME/кг×3 раза в нед. } \\
12000 \text { МЕ ×3 раза в нед. } \\
40000 \text { ME ×1 раз в нед. }\end{array}$ & $\begin{array}{l}30000 \text { ME } \times 1 \text { раз } \\
\text { в нед. }\end{array}$ & $\begin{array}{l}20000 \mathrm{ME} \times 1 \text { раз } \\
\text { в нед. }\end{array}$ & $\begin{array}{l}2,25 \text { мкг/кг ×1 раз } \\
\text { в нед. } \\
500 \text { мкг ×1 раз } \\
\text { в нед. }\end{array}$ \\
\hline $\begin{array}{l}\text { Снижение дозы } \\
\text { при достижении } \\
\text { целевого } \\
\text { уровня гемо- } \\
\text { глобина² }\end{array}$ & \multicolumn{4}{|l|}{ 25-50\% дозы } \\
\hline $\begin{array}{l}\text { Остановка } \\
\text { в лечении }\end{array}$ & \multicolumn{4}{|c|}{$\begin{array}{l}\text { При Нb > 130г/л следует приостановить введение препарата до снижения Нb до } \\
\text { уровня < } 120 \text { г/л }\end{array}$} \\
\hline $\begin{array}{l}\text { Отмена } \\
\text { препарата }\end{array}$ & \multicolumn{4}{|c|}{$\begin{array}{l}\text { Окончание XТ или отсутствие эффекта после } 8 \text { недель лечения (сохраняется } \\
\text { потребность в гемотрансфузиях) }\end{array}$} \\
\hline
\end{tabular}

1 Все эритропоэтины вводятся $\mathrm{n} / \kappa$.

2 Достижение уровня Нb 120г/л или увеличение уровня Нb более, чем на 20 г/л за 2 нед. 
Таблица 3. Рекомендуемые режимы внутривенного введения препаратов железа

\begin{tabular}{|c|c|c|}
\hline Препарат & Способ введения и дозировка & Тест-доза \\
\hline $\begin{array}{l}\text { Железа [III] } \\
\text { гидроксид } \\
\text { сахарозный } \\
\text { комплекс1 }\end{array}$ & $\begin{array}{l}\text { • В/в струйно: до } 200 \text { мг×3 раза в нед., } \\
\text { или в/в капельно до } 200 \text { мг×3 раза в нед., } \\
\text { минимальное время } 30 \text { мин., или } \\
\text { • В/в капельно: } 7 \text { мг/кг, однократная доза - } \\
\text { не более 500 мг железа; минимальное время } \\
\text { введения - 3,5 часа не чаще } 1 \text { раза в неделю. }\end{array}$ & Нет \\
\hline $\begin{array}{l}\text { Железа } \\
\text { карбокси- } \\
\text { мальтоза1 }\end{array}$ & $\begin{array}{l}\text { • В/в струйно } 15 \text { мг/кг или } \\
\text { - В/в капельно } 20 \text { мг/кг в максимальной } \\
\text { однократной дозе в неделю до } 1000 \text { мг железа; } \\
\text { минимальное время введения - } 15 \text { мин. }\end{array}$ & Нет \\
\hline $\begin{array}{l}\text { Железа [III] } \\
\text { гидроксид } \\
\text { декстран1 }\end{array}$ & $\begin{array}{l}\text { Зависит от точного типа декстрана, см. инструкцию } \\
\text { по применению. Минимальное время инфузии } \\
240-360 \text { мин. (4-6 ч.) }\end{array}$ & $\begin{array}{l}\text { В/в медленно (в течение 1-2 мин.) } \\
25 \text { мг или 0,5 мл препарата; время } \\
\text { ожидания - } 15 \text { мин., при отсут- } \\
\text { ствии нежелательных явлений } \\
\text { возможно введение полной дозы } \\
\text { с рекомендованной скоростью }\end{array}$ \\
\hline $\begin{array}{l}\text { Железа [III] } \\
\text { гидроксид } \\
\text { олигоизомаль- } \\
\text { тозат1 }\end{array}$ & $\begin{array}{l}\text { - До } 500 \text { мг внутривенно струйно до } 3 \text { раз } \\
\text { в неделю со скоростью до } 250 \text { мг железа/мин. } \\
\text { - В/в капельно } 20 \text { мг/кг строго в течение } 30 \text { мин; } \\
\text { после введения фиксированной дозы } 1000 \text { мг } \\
\text { через } 4 \text { недели повторная оценка необходимо- } \\
\text { сти дальнейшего применения по уровню Нb }\end{array}$ & Нет \\
\hline
\end{tabular}

1 Препараты железа не должны вводиться в дни введения противоопухолевых препаратов.

Таблица 4. Препараты, рекомендованные для лечения анемии у онкологических больных

\begin{tabular}{|c|c|}
\hline Группа & Препарат, начальная доза \\
\hline \multirow{4}{*}{$\begin{array}{l}\text { Эритропоэз- } \\
\text { стимулирую- } \\
\text { щие препараты }\end{array}$} & $\begin{array}{l}\text { Эпоэтин альфа } 150 \text { МЕ/кг×3 раза в нед. п/к } 12000 \text { ME×3 раза в нед. } \\
\text { п/к } 40000 \text { МЕ× } 1 \text { раз в нед. п/к }\end{array}$ \\
\hline & Эпоэтин бета 30000 ME×1 раз в нед. п/к \\
\hline & Эпоэтин тета 20000 ME×1 раз в нед. п/к \\
\hline & Дарбэпоэтин альфа 2,25 мкг/кг×1 раз в нед. п/к 500 мкг×1 раз в 3 нед. п/к \\
\hline \multirow[t]{4}{*}{$\begin{array}{l}\text { Препараты } \\
\text { железа }\end{array}$} & $\begin{array}{l}\text { Железа [III] гидроксидисахарозный комплекс в/в струйно до } 200 \text { мг×3 раза в нед., } \\
\text { или в/в капельно до } 200 \text { мг×3 раза в нед., минимальное время } 30 \text { мин., или в/в капельно } \\
7 \text { мг железа на кг массы тела, в однократной дозе не более } 500 \text { мг железа×1 раз } \\
\text { в неделю, в/в инфузия не менее } 3,5 \text { часов и не чаще } 1 \text { раза в неделю. }\end{array}$ \\
\hline & $\begin{array}{l}\text { Железа карбоксимальтозат в/в струйно: } 15 \text { мг/кг или в/в капельно } 20 \text { мг/кг в макси- } \\
\text { мально в однократной дозе } 1000 \text { мг в неделю; минимальное время введения-15 мин. }\end{array}$ \\
\hline & $\begin{array}{l}\text { Железа [III] гидроксид декстран зависит от точного типа декстрана, см. инструкцию } \\
\text { по применению. Минимальное время инфузии 240-360 мин. (4-6 ч.) }\end{array}$ \\
\hline & $\begin{array}{l}\text { Железа [II] гидроксид олигоизомальтозат до } 500 \text { мг×3 раз в нед. в/в струйно со } \\
\text { скоростью до } 250 \text { мг железа/мин.; в/в капельно } 20 \text { мг/кг строго в течение более } 30 \text { мин.; } \\
\text { после введения фиксированной дозы } 1000 \text { мг через } 4 \text { недели-повторная оценка } \\
\text { необходимости дальнейшего применения по уровне Нь. }\end{array}$ \\
\hline
\end{tabular}




\begin{tabular}{|l|l|}
\hline Группа & Препарат, начальная доза \\
\hline \multirow{2}{*}{ Витамины } & Цианкобаламин (Витамин В12) 0,5 мг/мл-1,0 мл, п/к через день \\
\cline { 2 - 3 } & Фолиевая кислота 2 мг/сут. внутрь \\
\hline
\end{tabular}

Гемоглобин $\leq 120$ г/л или снижение на $\geq 20$ г/л от базового уровня

\section{ДИФФЕРЕНЦИАЛЬНЫЙ ДИАГНОЗ АНЕМИИ}

- общий анализ крови с определением концентрации $\mathrm{Hb}$, гематокрита (Hct), количества эритроцитов и ретикулоцитов, среднего объема эритроцитов (MCV), среднего содержания Нb в эритроците (МСH) и средней концентрации Нb в эритроците (МСНC); кровотечение (кал на скрытую кровь, эндоскопическое обследование);

- гемолиз (проба Кумбса, ДВС-панель, гаптаглобин, непрямой билирубин, лДГ);

- алиментарная анемия (сывороточное железо, ОЖСС, ферритин, витамин В12, фолиевая кислота);

- наследственность (семейный анамнез);

- почечная дисфункция (клубочковая фильтрация);

- миелосупрессия, вызванная противоопухолевой терапией (лТ, ХT);

- метастатическое поражение костного мозга

\section{ЛЕЧЕНИЕ АНЕМИИ В ЗАВИСИМОСТИ ОТ ДОМИНИРУЮЩЕЙ ПРИЧИНЫ}

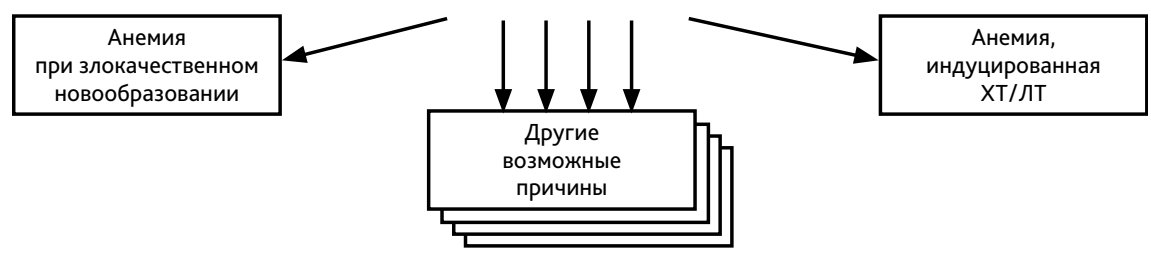

Рисунок 1. Рекомендуемый алгоритм обследования онкологического больного с анемией. 


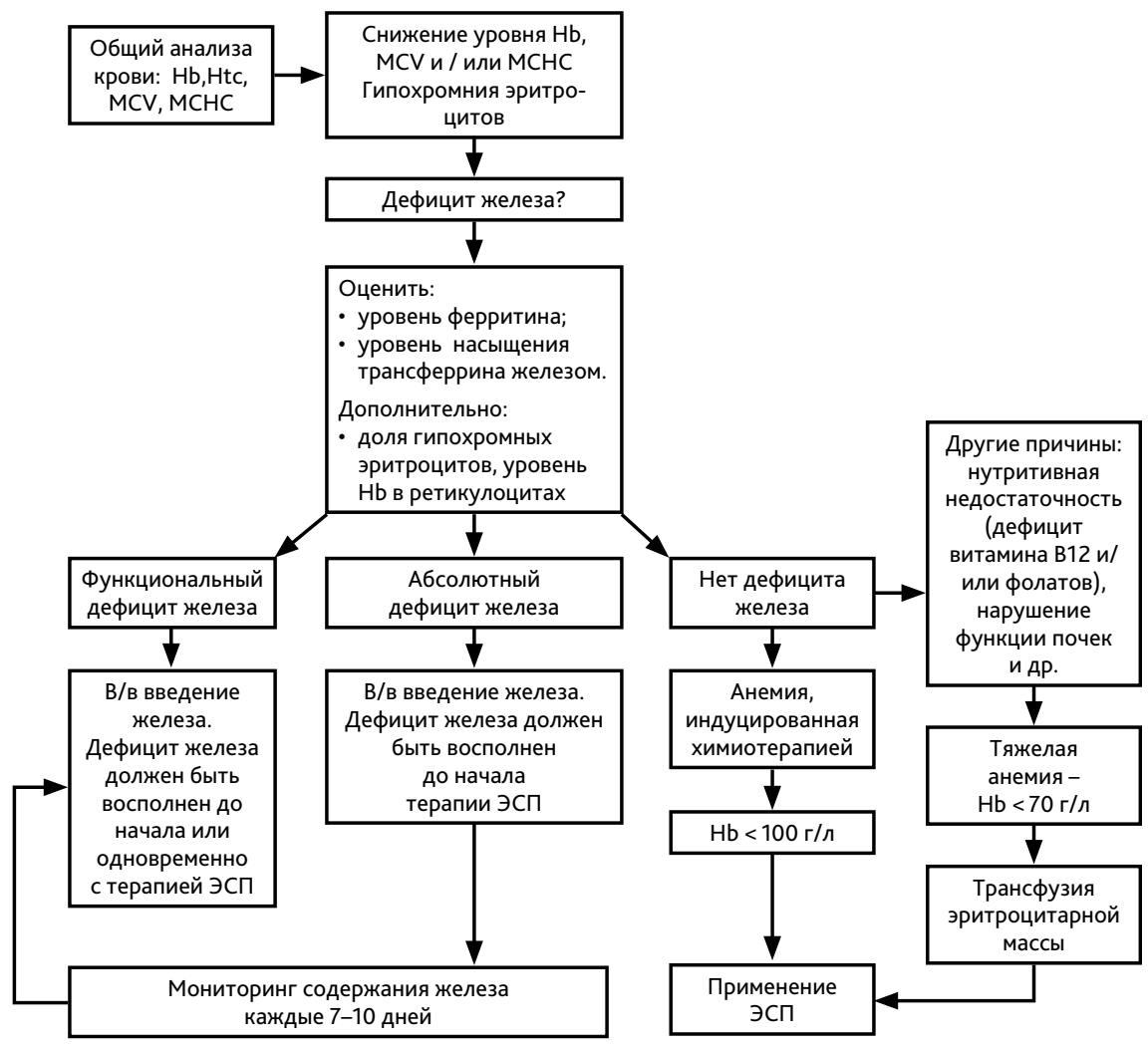

Рисунок 2. Рекомендуемый алгоритм лечения анемии у онкологических больных. 